\title{
THE INDEX OF A SUBGROUP OF THE SYMPLECTIC MODULAR GROUP
}

\author{
Edward Spence
}

\section{INTRODUCTION}

Let $\Omega_{\mathrm{n}}$ be the semigroup of all $\mathrm{n}$-by-n matrices with rational integral entries, and let . $\|_{\mathrm{n}}$ denote the symplectic modular group of degree $\mathrm{n}$; that is, let $\|_{\mathrm{n}}$ be the group of all matrices $M \epsilon \Omega_{2 n}$ that satisfy the equation

$$
\mathrm{M}^{\prime} \mathrm{JM}=\mathrm{J} \text {, }
$$

where $J=\left[\begin{array}{rr}0 & I \\ -I & 0\end{array}\right], I$ being the identity $n-b y-n$ matrix. If $M \epsilon \mathscr{N}_{\mathrm{n}}$ is partitioned as $\left[\begin{array}{ll}A & B \\ C & D\end{array}\right]$ with $A, B, C, D \in \Omega_{n}$, it is easy to see that (1) is equivalent to the conditions

$$
\mathrm{AB}^{\prime}=\mathrm{BA}^{\prime}, \quad \mathrm{CD}^{\prime}=\mathrm{DC}^{\prime}, \quad \text { and } \quad \mathrm{AD}^{\prime}-\mathrm{BC}^{\prime}=\mathrm{I} \text {. }
$$

A matrix $\mathrm{N} \in \Omega_{2 \mathrm{n}}$ is called $\mathrm{m}$-symplectic ( $\mathrm{m}$ a positive integer) if it satisfies the condition

$$
N^{\prime} J N=m J .
$$

Denote the set of m-symplectic matrices by $\|_{n}(m)$, and call two matrices $\mathrm{M}, \mathrm{N} \in \|_{\mathrm{n}}(\mathrm{m})$ left-associated if there exists an $\mathrm{M}_{1} \in \|_{\mathrm{n}}$ such that $\mathrm{M}=\mathrm{M}_{1} \mathrm{~N}$, and equivalent if there exist $M_{2}, M_{3} \in \mathscr{I} n$ such that $M=M_{2} N_{3}$. Clearly, the relations of being left-associated and of being equivalent are equivalence relations on $\mathscr{A l}_{\mathrm{n}}(\mathrm{m})$. In [5], the following two results were proved.

THEOREM 1. An m-symplectic matrix is left-associated to exactly one matrix of the form

$$
\left[\begin{array}{cc}
\mathrm{Q}_{1} & \mathrm{~m}^{-1} \mathrm{SQ} \\
0 & \mathrm{Q}_{2}
\end{array}\right],
$$

where $\mathrm{Q}_{1}, \mathrm{Q}_{2}, \mathrm{~S} \in \Omega_{\mathrm{n}}, \mathrm{Q}_{1}$ is in Hermite normal form, $\operatorname{det} \mathrm{Q}_{1}>0, \mathrm{Q}_{1} \mathrm{Q}_{2}^{\prime}=\mathrm{mI}$, $\mathrm{S}=\left[\mathrm{s}_{\mathrm{ij}}\right]$ is symmetric, $0 \leq \mathrm{s}_{\mathrm{ij}}<\mathrm{m}(1 \leq \mathrm{i}, \mathrm{j} \leq \mathrm{n})$, and $\mathrm{SQ}_{2} \equiv 0(\bmod \mathrm{m})$.

The Hermite normal form of a matrix in $\Omega_{\mathrm{n}}$ is the unique form to which it can be reduced by premultiplication by a suitable $U \in \Omega_{\mathrm{n}}$ with determinant unity. For a more detailed explanation, see [2, p. 32].

Received February 12, 1971.

This paper was written while the author was on leave of absence at the University of Illinois.

Michigan Math. J. 19 (1972). 
THEOREM 2. Every m-symplectic matrix is equivalent to exactly one matrix of the form

$$
\operatorname{diag}\left\{d_{1}, d_{2}, \cdots, d_{2 n}\right\} \text {, }
$$

where

(4) $\mathrm{d}_{\mathrm{j}}>0(1 \leq \mathrm{j} \leq 2 \mathrm{n}), \quad \mathrm{d}_{\mathrm{i}}\left|\mathrm{d}_{\mathrm{i}+\mathrm{l}}(1 \leq \mathrm{i}<\mathrm{n}), \quad \mathrm{d}_{\mathrm{k}}^{2}\right| \mathrm{m}, \quad$ and $\mathrm{d}_{\mathrm{k}} \mathrm{d}_{\mathrm{n}+\mathrm{k}}=\mathrm{m} \quad(1 \leq \mathrm{k} \leq \mathrm{n})$.

The number of canonical forms in either case was also found in [5]. In the present paper, we obtain an alternate method of finding the number of canonical forms given in Theorem 1 , by investigating certain subgroups of $\mathscr{M}_{\mathrm{n}}$.

It is clear that if $\mathrm{M}_{1}, \mathrm{M}_{2} \epsilon \mathscr{N}_{\mathrm{n}}(\mathrm{m})$ are left-associated, then they are also equivalent. Suppose, conversely, that $M_{1}, M_{2} \in \mathscr{I}_{\mathrm{n}}(\mathrm{m})$ are equivalent. Then there exist $\mathrm{U}_{1}, \mathrm{U}_{2}, \mathrm{~V}_{1}, \mathrm{~V}_{2} \in \mathscr{I}_{\mathrm{n}}$ such that

$$
\mathrm{M}_{1}=\mathrm{U}_{1} \mathrm{DV}_{1}, \quad \mathrm{M}_{2}=\mathrm{U}_{2} \mathrm{DV}_{2} \text {, }
$$

where $D=\operatorname{diag}\left\{d_{1}, d_{2}, \cdots, d_{2 n}\right\}$ satisfies conditions (4). Thus $M_{1}$ and $M_{2}$ are left-associated if and only if there exists $U \in \mathscr{A}_{\mathrm{n}}$ such that the equivalent conditions

$$
\mathrm{U}_{1} \mathrm{DV}_{1}=\mathrm{UU}_{2} \mathrm{DV}_{2}, \quad \mathrm{D}^{-1}\left(\mathrm{UU}_{2}\right)^{-1} \mathrm{U}_{1} \mathrm{D}=\mathrm{v}_{2} \mathrm{~V}_{1}^{-1}, \quad \mathrm{~V}_{2} \mathrm{~V}_{1}^{-1} \in \mathrm{D}^{-1} \varkappa_{\mathrm{n}} \mathrm{D} \cap \|_{\mathrm{n}}
$$

are satisfied. Since $\mathrm{D}^{-1} \mathscr{H}_{\mathrm{n}} \mathrm{D} \cap \mathscr{H}_{\mathrm{n}}$ is a subgroup of $\mathscr{H}_{\mathrm{n}}$, we can rephrase the third condition by saying that $\mathrm{V}_{1}$ and $\mathrm{V}_{2}$ belong to the same right coset of $D^{-1} \mathscr{H}_{\mathrm{n}} \mathrm{D} \cap \mathscr{U}_{\mathrm{n}}$ in $\mathscr{\prime}_{\mathrm{n}}$. Write

$$
\left[\left\|_{n}: D^{-1}\right\|_{n} D \cap \|_{n}\right]=A_{2 n}\left(d_{1}, d_{2}, \cdots, d_{2 n}\right)
$$

Then, for each set of positive integers $d_{1}, d_{2}, \cdots, d_{2 n}$ satisfying (4), the number of matrices of the form UDV (with $U, V \in \mathscr{l}_{\mathrm{n}}$ ) that are not left-associated is $A_{2 n}\left(d_{1}, d_{2}, \cdots, d_{2 n}\right)$. Since nonequivalent matrices are not left-associated, we have the following result.

THEOREM 3. Let $\mathrm{h}_{\mathrm{n}}(\mathrm{m})$ denote the number of canonical forms under the relation of being left-associated. Then

$$
\mathrm{h}_{\mathrm{n}}(\mathrm{m})=\sum \mathrm{A}_{2 \mathrm{n}}\left(\mathrm{d}_{1}, \mathrm{~d}_{2}, \cdots, \mathrm{d}_{2 \mathrm{n}}\right)
$$

where the summation is taken over all sets of positive integers $\mathrm{d}_{1}, \mathrm{~d}_{2}, \cdots, \mathrm{d}_{2 \mathrm{n}}$ satisfying conditions (4).

\section{EVALUATION OF $h_{n}(m)$}

It was shown in [5] that $h_{n}(m)$ is multiplicative, in other words, that $h_{n}\left(m_{1} m_{2}\right)=h_{n}\left(m_{1}\right) h_{n}\left(m_{2}\right)$ if $\left(m_{1}, m_{2}\right)=1$. It follows that to evaluate $h_{n}(m)$, we need only consider the case where $m=p^{\alpha}$ ( $p$ a prime). Here,

$$
\mathrm{h}_{\mathrm{n}}\left(\mathrm{p}^{\alpha}\right)=\sum \mathrm{A}_{2 \mathrm{n}}\left(\mathrm{p}^{\alpha}, \mathrm{p}^{\alpha_{2}}, \cdots, \mathrm{p}^{\alpha_{2 \mathrm{n}}}\right)
$$

the summation being over all $2 \mathrm{n}$-tuples $\left(\alpha_{1}, \alpha_{2}, \cdots, \alpha_{2 n}\right)$ of nonnegative integers satisfying the conditions 
(5)

$$
0 \leq \alpha_{1} \leq \cdots \leq \alpha_{\mathrm{n}}, \quad 2 \alpha_{\mathrm{i}} \leq \alpha, \quad \text { and } \quad \alpha_{\mathrm{i}}+\alpha_{\mathrm{n}+\mathrm{i}}=\alpha \quad(1 \leq \mathrm{i} \leq \mathrm{n})
$$

Suppose therefore that $E$ is the matrix $\operatorname{diag}\left\{p^{\alpha_{1}}, p^{\alpha_{2}}, \cdots, p^{\alpha_{2 n}}\right\}$ with $\alpha_{1}, \alpha_{2}, \cdots, \alpha_{2 n}$ satisfying (5), and write $\mathrm{K}_{\mathrm{n}}$ for the group $\mathrm{E}^{-1} \mathscr{\prime}_{\mathrm{n}} \mathrm{E} \cap \mathscr{I}_{\mathrm{n}}$. Also, let $\mathscr{H}_{\mathrm{n}}[\mathrm{q}]$ denote the principal congruence subgroup of $\mathscr{A}_{\mathrm{n}}$ defined by

$$
\mathscr{N}_{\mathrm{n}}[\mathrm{q}]=\left\{\mathrm{M} \in \mathscr{N}_{\mathrm{n}}: \mathrm{M} \equiv \mathrm{I}(\bmod \mathrm{q})\right\} .
$$

It is well known $\left[4\right.$, p. 58] that $\mathscr{N}_{\mathrm{n}}[\mathrm{q}]$ is a normal subgroup of $\mathscr{N}_{\mathrm{n}}$ of finite index

$$
\left[\mathscr{N} \|_{n}: \mathscr{N}_{\mathrm{n}}[\mathrm{q}]\right]=\mathrm{q}^{\mathrm{n}(2 \mathrm{n}+1)} \prod_{\mathrm{p} \mid \mathrm{q} k=1}^{\mathrm{n}} \prod_{k=1}\left(1-\mathrm{p}^{-2 k}\right)
$$

LEMMA 1. If $\mathrm{q}=\mathrm{p} \beta$, where $\beta \geq \alpha$, then $\|_{\mathrm{n}}[\mathrm{q}] \subseteq \mathrm{K}_{\mathrm{n}}$.

The proof is entirely straightforward, and we omit it.

It is an immediate consequence of Lemma 1 that

$$
\left[\mathscr{H} \|_{\mathrm{n}}: \mathrm{K}_{\mathrm{n}}\right]=\left[\mathscr{H}_{\mathrm{n}}: \mathscr{H}_{\mathrm{n}}[\mathrm{q}]\right] /\left[\mathrm{K}_{\mathrm{n}}: \mathscr{H}_{\mathrm{n}}[\mathrm{q}]\right]
$$

when $\mathrm{q}=\mathrm{p}^{\beta}$ (as it will be throughout the remainder of the paper), and since [e/ $\left.\left\|_{n}:\right\|_{n}[\mathrm{q}]\right]$ is known, the problem of determining

$$
\mathrm{A}_{2 \mathrm{n}}\left(\mathrm{p}^{\alpha}, \mathrm{p}^{\alpha}, \cdots, \mathrm{p}^{\left.\alpha_{2 \mathrm{n}}\right)}=\left[\|_{\mathrm{n}}: \mathrm{K}_{\mathrm{n}}\right]\right.
$$

has been reduced to the evaluation of $\left[K_{n}: \|_{n}[q]\right]$. A matrix $M \in \Omega_{2 n}$ is said to be symplectic modulo $\mathrm{q}$ if

$$
M^{\prime} J M \equiv J(\bmod q)
$$

If $\mathrm{M}$ is symplectic modulo $\mathrm{q}$, then by Theorem 1 of [3] there exists an $\mathrm{N} \epsilon \mathscr{A l}_{\mathrm{n}}$ such that $N \equiv M(\bmod q)$.

LEMMA 2. $\left[\mathrm{K}_{\mathrm{n}}: \|_{\mathrm{n}}[\mathrm{q}]\right]$ is the number of matrices $\mathrm{M}=\left[\begin{array}{ll}\mathrm{A} & \mathrm{B} \\ \mathrm{C} & \mathrm{D}\end{array}\right] \epsilon \Omega_{2 \mathrm{n}}$ that are incongruent $(\bmod \mathrm{q})$ and symplectic modulo $\mathrm{q}$, and whose entries satisfy (in the obvious notation) the conditions

$$
\begin{cases}\mathrm{a}_{\mathrm{ij}} \equiv 0\left(\bmod \mathrm{p}^{\alpha_{\mathrm{j}}-\alpha_{\mathrm{i}}}\right) & (1 \leq \mathrm{i} \leq \mathrm{j} \leq \mathrm{n}) \\ \mathrm{b}_{\mathrm{ij}} \equiv 0\left(\bmod \mathrm{p}^{\alpha-\alpha_{\mathrm{i}}-\alpha_{\mathrm{j}}}\right) & (1 \leq \mathrm{i}, \mathrm{j} \leq \mathrm{n}) \\ \mathrm{d}_{\mathrm{ij}} \equiv 0\left(\bmod \mathrm{p}^{\left.\alpha_{\mathrm{i}}-\alpha_{\mathrm{j}}\right)}\right. & (1 \leq \mathrm{j} \leq \mathrm{i} \leq \mathrm{n})\end{cases}
$$

Proof. Suppose that $M=\left[\begin{array}{ll}A & B \\ C & D\end{array}\right] \in \Omega_{2 n}$ is symplectic modulo $q$ and satisfies (6). Then there exists $N \in \mathscr{I}_{\mathrm{n}}$ such that $N \equiv M(\bmod q)$. Since $\alpha_{1}, \alpha_{2}, \cdots, \alpha_{n}$ satisfy (5), it is easy to see that the entries of $N$ also satisfy conditions (6), and by a simple exercise this implies that $N \in \mathrm{K}_{\mathrm{n}}$. To complete the proof, observe that $N_{1}, N_{2} \in K_{n}$ lie in distinct cosets of $\mathscr{N}_{n}[q]$ in $K_{n}$ if and only if $N_{1} \neq N_{2}(\bmod q)$. 
Let the set of matrices $M=\left[\begin{array}{ll}A & B \\ C & D\end{array}\right] \in \Omega_{2 n}$ that are symplectic modulo $q$ and whose entries satisfy (6) be denoted by $L_{n}\left(\alpha ; \alpha_{1}, \alpha_{2}, \cdots, \alpha_{n}\right)$, so that $\mathrm{M} \in \mathrm{L}_{\mathrm{n}}\left(\alpha ; \alpha_{1}, \alpha_{2}, \cdots, \alpha_{\mathrm{n}}\right)$ implies the existence of an $\mathrm{N}$ in $\mathrm{K}_{\mathrm{n}}$ such that $\mathrm{N} \equiv \mathrm{M}(\bmod q)$. Also, write $\ell_{\mathrm{n}}\left(\alpha ; \alpha_{1}, \alpha_{2}, \cdots, \alpha_{\mathrm{n}}\right)$ for the number of matrices in $\mathrm{L}_{\mathrm{n}}\left(\alpha ; \alpha_{1}, \alpha_{2}, \cdots, \alpha_{\mathrm{n}}\right)$ that are incongruent $(\bmod \mathrm{q})$. Then

$$
\ell_{n}\left(\alpha ; \alpha_{1}, \alpha_{2}, \cdots, \alpha_{n}\right)=\left[\mathrm{K}_{\mathrm{n}}: \mathscr{l}_{\mathrm{n}}(\mathrm{q})\right],
$$

by the lemima.

At this stage, assume that

$$
\left(\alpha_{1}, \alpha_{2}, \cdots, \alpha_{n}\right) \equiv(\underbrace{\mathrm{a}_{1}, \cdots, \mathrm{a}_{1}}_{\mathrm{r}_{1} \text { terms }}, \underbrace{\mathrm{a}_{2}, \cdots, \mathrm{a}_{2}}_{\mathrm{r}_{2} \text { terms }}, \cdots, \underbrace{\mathrm{a}_{\mathrm{k}}, \cdots, \mathrm{a}_{\mathrm{k}}}_{\mathrm{r}_{\mathrm{k}} \text { terms }})
$$

where $\alpha_{1}=\mathrm{a}_{1}<\mathrm{a}_{2}<\cdots<\mathrm{a}_{\mathrm{k}}=\alpha_{\mathrm{n}}$ and $\mathrm{r}_{1}+\mathrm{r}_{2}+\cdots+\mathrm{r}_{\mathrm{k}}=\mathrm{n}, \mathrm{r}_{\mathrm{i}} \geq 1$.

THEOREM 4.

$\left[\mathrm{K}_{\mathrm{n}}: \mathscr{\prime l}_{\mathrm{n}}[\mathrm{q}]\right]$

$$
=\left\{\begin{array}{c}
q^{n(2 n+1)} p^{-\alpha n(n+1) / 2} \prod_{j=1}^{n} p^{2(n+1-j) \alpha_{j}} \prod_{i=1}^{k}\left\{\prod_{j=1}^{r_{i}}\left(1-p^{-j}\right)\right\} \text { if } 2 \alpha_{n}<\alpha, \\
q^{n(2 n+1)} p^{-\alpha n(n+1) / 2} \prod_{j=1}^{n} p^{2(n+1-j) \alpha_{j}} \prod_{i=1}^{k-1}\left\{\prod_{j=1}^{r_{i}\left(1-p^{-j}\right)}\right\} \cdot \prod_{j=1}^{r_{k}}\left(1-p^{-2 j}\right) \\
\text { if } 2 \alpha_{n}=\alpha .
\end{array}\right.
$$

Proof. Let $\mathrm{M}=\left[\begin{array}{cc}\mathrm{A} & \mathrm{B} \\ \mathrm{C} & \mathrm{D}\end{array}\right] \in \mathrm{L}_{\mathrm{n}}\left(\alpha ; \alpha_{1}, \alpha_{2}, \cdots, \alpha_{\mathrm{n}}\right)$. Then, since

$$
\left(a_{11}, \cdots, a_{1 n}, b_{11}, \cdots, b_{1 n}, q\right)=1,
$$

there exist integers $\lambda_{1}, \lambda_{2}, \cdots, \lambda_{2 n}$ such that

$$
\lambda_{1} a_{11}+\cdots+\lambda_{n} a_{1 n}+\lambda_{n+1} b_{11}+\cdots+\lambda_{2 n} b_{1 n} \equiv 1(\bmod q)
$$

with $\left(\lambda_{1}, q\right)=1($ see $[1$, Lemma 2$])$. Write

$$
\mathrm{U}_{1}=\left[\begin{array}{ccccc}
\lambda_{1} & 0 & \cdots & 0 & 0 \\
\lambda_{2} & 1 & \cdots & 0 & 0 \\
\cdots & \cdots & \cdots & \cdots & \cdots \\
\lambda_{\mathrm{n}-1} & 0 & \cdots & 1 & 0 \\
\lambda_{\mathrm{n}} & 0 & \cdots & 0 & \lambda_{1}^{-1}
\end{array}\right]
$$


where $\lambda_{1}^{-1}$ is the inverse of $\lambda_{1}(\bmod q)$, and let $v_{1}$ be a matrix such that $\mathrm{U}_{1} \mathrm{~V}_{1}^{\prime} \equiv \mathrm{I}(\bmod \mathrm{q})$. Such a matrix exists, since $\operatorname{det} \mathrm{U}_{1} \equiv 1(\bmod \mathrm{q})$. Further, let

$$
\mathrm{X} \equiv \lambda_{1}^{-1}\left[\begin{array}{c}
\lambda_{\mathrm{n}+2}-\lambda_{2} \\
\lambda_{\mathrm{n}+3}-\lambda_{3} \\
\cdots \\
\lambda_{2 \mathrm{n}}-\lambda_{\mathrm{n}}
\end{array}\right](\bmod \mathrm{q})
$$

and choose $\mathrm{s}$ so that

$$
\mathrm{s} \equiv \lambda_{1}^{-1}\left(\lambda_{\mathrm{n}+1}-\left[\lambda_{2}, \lambda_{3}, \cdots, \lambda_{\mathrm{n}}\right] \mathrm{X}\right)(\bmod \mathrm{q}) .
$$

Then $S=\left[\begin{array}{ll}S & X^{\prime} \\ X & I\end{array}\right]$ is symmetric and

$$
\mathrm{SU}_{1} \equiv\left[\begin{array}{cc}
\lambda_{\mathrm{n}+1} & \\
\lambda_{\mathrm{n}+2} & \\
\cdots \\
\lambda_{2 \mathrm{n}}
\end{array}\right](\bmod \mathrm{q}) .
$$

It follows that $M_{1}=\left[\begin{array}{cc}U_{1} & 0 \\ S_{1} & V_{1}\end{array}\right]$ is symplectic modulo $q$ and

$$
\mathrm{MM}_{1} \equiv\left[\begin{array}{cc}
1 & * \\
* & *
\end{array}\right](\bmod \mathrm{q}) .
$$

Note that since $U_{l}$ is a lower-triangular matrix, $V_{l}$ may be taken to be uppertriangular, and hence the entries of $M_{1}$ satisfy conditions (6); that is, $\mathrm{M}_{1} \in \mathrm{L}_{\mathrm{n}}\left(\alpha ; \alpha_{1}, \alpha_{2}, \cdots, \alpha_{\mathrm{n}}\right)$ and there exists an $\mathrm{M}_{2} \in \mathrm{K}_{\mathrm{n}}$ such that $M_{2} \equiv M_{1}(\bmod q)$. Thus

$$
\mathrm{MM}_{2} \equiv\left[\begin{array}{cc}
1 & * \\
* & *
\end{array}\right](\bmod \mathrm{q}) \quad\left(\mathrm{M}_{2} \in \mathrm{K}_{\mathrm{n}}\right)
$$

Suppose that the first row of $\mathrm{MM}_{2}$ is congruent to

$$
\left(1, a_{12}^{\prime}, \cdots, a_{1 n}^{\prime}, b_{11}^{\prime}, \cdots, b_{1 n}^{\prime}\right)(\bmod q)
$$

so that

$$
a_{1 j}^{\prime} \equiv 0\left(\bmod p^{\alpha_{j}-\alpha_{1}}\right) \quad \text { and } \quad b_{1 j}^{\prime} \equiv 0\left(\bmod p^{\alpha-\alpha_{j}-\alpha_{1}}\right) .
$$

Let $\mathrm{U}_{2}$ be the unimodular matrix 


$$
\mathrm{U}_{2}=\left[\begin{array}{cccc}
1 & -\mathrm{a}_{12}^{\prime} & \cdots & \mathrm{a}_{1 \mathrm{n}}^{\prime} \\
0 & 1 & \cdots & 0 \\
\cdots & \cdots & \cdots & \cdots \\
0 & 0 & \cdots & 1
\end{array}\right] \text {, }
$$

and let $\mathrm{T}=\left[\mathrm{t}_{\mathrm{ij}}\right] \in \Omega_{\mathrm{n}}$ be the symmetric matrix defined by

$$
\begin{aligned}
& t_{11}=-\left(b_{11}^{\prime}+b_{12}^{\prime} a_{12}^{\prime}+\cdots+b_{1 n}^{\prime} a_{1 n}^{\prime}\right), \quad t_{1 j}=-b_{1 j}^{\prime} \quad(1<j \leq n), \\
& t_{i j}=\delta_{i j} p^{\alpha-2 \alpha_{j}} \quad(1<i, j \leq n) \quad\left(\delta_{i j} \text { is the Kronecker delta }\right) .
\end{aligned}
$$

Then $M_{3}=\left[\begin{array}{cc}U_{2} & U_{2}^{T} \\ 0 & U_{2}^{1}-1\end{array}\right] \epsilon \mathscr{M}_{n}$; in fact, careful examination shows that $M_{3} \in K_{n}$; that is, the entries of $\overrightarrow{M_{3}}$ satisfy condition (6). For if $U_{2} T=\left[t_{i j}^{\prime}\right]$, then

$$
\begin{gathered}
t_{11}^{\prime}=-b_{11}^{\prime}, \quad t_{1 j}^{\prime}=-b_{1 j}^{\prime}-a_{1 j}^{\prime} p^{\alpha-2 \alpha_{j}} \quad(1<j \leq n), \quad t_{i 1}^{\prime}=-b_{1 i}^{\prime} \quad(1<i \leq n), \\
t_{i j}^{\prime}=\delta_{i j} p^{\alpha-2 \alpha_{j}} \quad(1<i, j \leq n),
\end{gathered}
$$

and as a result of $(7)$ we easily see that $t_{i j}^{\prime} \equiv 0\left(\bmod p^{\alpha-\alpha_{i}-\alpha_{j}}\right)(1 \leq i, j \leq n)$. We also see that the entries of $\mathrm{U}_{2}$ and $\mathrm{U}_{2}^{\prime-1}$ satisfy the required conditions. Hence $\mathrm{MM}_{2} \mathrm{M}_{3} \equiv\left[\begin{array}{cc}1 & 0 \\ * & *\end{array}\right](\bmod \mathrm{q})$, with $\mathrm{M}_{2} \mathrm{M}_{3} \in \mathrm{K}_{\mathrm{n}}$.

However, $\mathrm{M} \mathrm{M}_{2} \mathrm{M}_{3}$ is symplectic modulo $\mathrm{q}$, and hence

$$
\mathrm{MM}_{4} \equiv\left[\begin{array}{cccc}
1 & 0 & 0 & 0 \\
\mathrm{Z}^{\prime} & \mathrm{A}_{1} & 0 & \mathrm{~B}_{1} \\
\mathrm{c} & \mathrm{X} & 1 & \mathrm{Y} \\
\mathrm{W}^{\prime} & \mathrm{C}_{1} & 0 & \mathrm{D}_{1}
\end{array}\right](\bmod \mathrm{q})
$$

where $M_{4}=M_{2} M_{3} \in K_{n}, A_{1}, B_{1}, C_{1}, D_{1} \in \Omega_{n-1}$, and X, Y, Z, W are row vectors of dimension $\mathrm{n}-1$. Since $\mathrm{MM}_{4} \in \mathrm{L}_{\mathrm{n}}\left(\alpha ; \alpha_{1}, \alpha_{2}, \cdots, \alpha_{\mathrm{n}}\right)$, it is readily verified that $\left[\begin{array}{ll}\mathrm{A}_{1} & \mathrm{~B}_{1} \\ \mathrm{C}_{1} & \mathrm{D}_{1}\end{array}\right] \in \mathrm{L}_{\mathrm{n}-1}\left(\alpha ; \alpha_{2}, \cdots, \alpha_{\mathrm{n}}\right)$ and

$$
\left[\begin{array}{ll}
\mathrm{X} & \mathrm{Y}
\end{array}\right] \equiv[\mathrm{Z} \mathrm{W}]\left[\begin{array}{cc}
-\mathrm{C}_{1} & -\mathrm{D}_{1} \\
\mathrm{~A}_{1} & \mathrm{~B}_{1}
\end{array}\right](\bmod \mathrm{q})
$$

in other words, $\mathrm{X}$ and $\mathrm{Y}$ are uniquely determined $(\bmod \mathrm{q})$ by $\mathrm{A}_{1}, \mathrm{~B}_{1}, \mathrm{C}_{1}, \mathrm{D}_{1}, \mathrm{Z}$, and $\mathrm{W}$.

An analysis of the construction of $\mathrm{M}_{4}$ shows that it depends only on the first row of $\mathrm{M}$, so that if the first row of $\mathrm{N} \in \mathrm{L}_{\mathrm{n}}\left(\alpha ; \alpha_{1}, \alpha_{2}, \cdots, \alpha_{\mathrm{n}}\right)$ is congruent $(\bmod \mathrm{q})$ to the first row of $\mathrm{M}$, then $\mathrm{NM}_{4} \equiv\left[\begin{array}{ll}1 & 0 \\ * & *\end{array}\right](\bmod \mathrm{q})$. It follows that, 
corresponding to each $\left[\begin{array}{ll}A_{1} & B_{1} \\ C_{1} & D_{1}\end{array}\right]$ in $L_{n-1}\left(\alpha ; \alpha_{2}, \cdots, \alpha_{n}\right)$, each set of row vectors $\mathrm{X}, \mathrm{Y}, \mathrm{Z}, \mathrm{W}$ of dimension $\mathrm{n}-1$ related by (9), and any preassigned first row of $\mathrm{M}$, the other rows of $M$ are uniquely determined $(\bmod q)$. Thus

$$
q^{2 n-1} \ell_{n-1}\left(\alpha ; \alpha_{2}, \cdots, \alpha_{n}\right)
$$

is the number of incongruent $(\bmod q)$ matrices in $L_{n}\left(\alpha ; \alpha_{1}, \cdots, \alpha_{n}\right)$ whose first rows are congruent $(\bmod q)$ (since there are $q^{2 n-1}$ choices for $\mathrm{Z}, \mathrm{W}$, and $\mathrm{c}$ ).

We now examine the number of possible incongruent $(\bmod q)$ choices of a first row of a matrix in $\mathrm{L}_{\mathrm{n}}\left(\alpha ; \alpha_{1}, \cdots, \alpha_{\mathrm{n}}\right)$. This is the number of 2 -tuples $\left(a_{11}, \cdots, a_{1 n}, b_{11}, \cdots, b_{1 n}\right)$ of integers in a complete system of residues (mod $q$ ) such that

$$
\begin{cases} & \left(a_{11}, a_{12}, \cdots, a_{1 n}, b_{11}, b_{12}, \cdots, b_{1 n}, q\right)=1 \\ \text { and } & \\ & a_{1 j} \equiv 0\left(\bmod p^{\alpha-\alpha_{1}}\right), \quad b_{1 j} \equiv 0\left(\bmod p^{\left.\alpha-\alpha_{1}-\alpha_{j}\right)} \quad(1 \leq j \leq n) .\right.\end{cases}
$$

Case (i). $2 \alpha_{\mathrm{n}}<\alpha$.

Here $\alpha-\alpha_{1}-\alpha_{\mathrm{j}} \neq 0$ for any $\mathrm{j}$, since $\alpha_{1}+\alpha_{\mathrm{j}} \leq 2 \alpha_{\mathrm{n}}$, and it is obvious that (11) is satisfied if and only if $\left(a_{11}, \cdots, a_{i_{1}}, q\right)=1$ and

$$
a_{1 j} \equiv 0\left(\bmod p^{\alpha_{j}-\alpha_{1}}\right), \quad b_{1 j} \equiv 0\left(\bmod p^{\left.\alpha-\alpha_{1}-\alpha_{j}\right)} \quad(1 \leq j \leq n)\right.
$$

Since the number of incongruent $(\bmod q)$ solutions of $\left(a_{11}, \cdots, a_{1 r_{1}}, q\right)=1$ is $q^{r} 1\left(1-p^{-r} 1\right)$, it follows immediately that the number of incongruent (mod $q$ ) solutions of (11) is

$$
\mathrm{q}^{\mathrm{r}_{1}}\left(1-\mathrm{p}^{-\mathrm{r}_{1}}\right) \prod_{\mathbf{j}>\mathrm{r}_{1}} \mathrm{p}^{\beta-\alpha_{\mathrm{j}}+\alpha_{1}} \prod_{\mathrm{j}=1}^{\mathrm{n}} \mathrm{p}^{\beta-\alpha+\alpha_{1}+\alpha_{j}}
$$

We can simplify the last expression to

$$
\mathrm{q}^{2 \mathrm{n}}\left(1-\mathrm{p}^{-\mathrm{r}}\right) \mathrm{p}^{2 \mathrm{n} \alpha_{1}-\mathrm{n} \alpha}
$$

Thus, by (10),

$$
\ell_{n}\left(\alpha ; \alpha_{1}, \cdots, \alpha_{n}\right)=q^{4 n-1}\left(1-p^{-r} 1\right) p^{2 n \alpha_{1}-n \alpha} \ell_{n-1}\left(\alpha ; \alpha_{2}, \cdots, \alpha_{n}\right),
$$

and an easy induction argument proves the first part of the theorem.

Case (ii). $2 \alpha_{\mathrm{n}}=\alpha$.

The induction argument used above works until we reach the stage $\ell_{r_{k}}\left(\alpha ; \alpha_{n}, \cdots, \alpha_{n}\right)$. Observe that when $2 \alpha_{1}=2 \alpha_{2}=\cdots=2 \alpha_{n}=\alpha$, the number of solutions of (11) is precisely $q^{2 n}\left(1-p^{-2 n}\right)$. Thus, putting $n=r_{k}$, we obtain the formula 


$$
\begin{aligned}
\ell_{r_{k}}\left(\alpha ; \alpha_{n}, \cdots, \alpha_{n}\right) & =q^{4 r_{k}-1}\left(1-p^{\left.-2 r_{k}\right)} \ell_{r_{k}-1}\left(\alpha ; \alpha_{n}, \cdots, \alpha_{n}\right)\right. \\
& =q^{{ }^{r_{k}\left(2 r_{k}+1\right)}} \prod_{j=1}\left(1-p^{-2 j}\right)
\end{aligned}
$$

by induction. This completes the proof.

The following is an immediate consequence of Lemma 1 and Theorem 4.

\section{COROLLARY 1.}

$\left[\mathscr{M}_{\mathrm{n}}: \mathrm{K}_{\mathrm{n}}\right]$

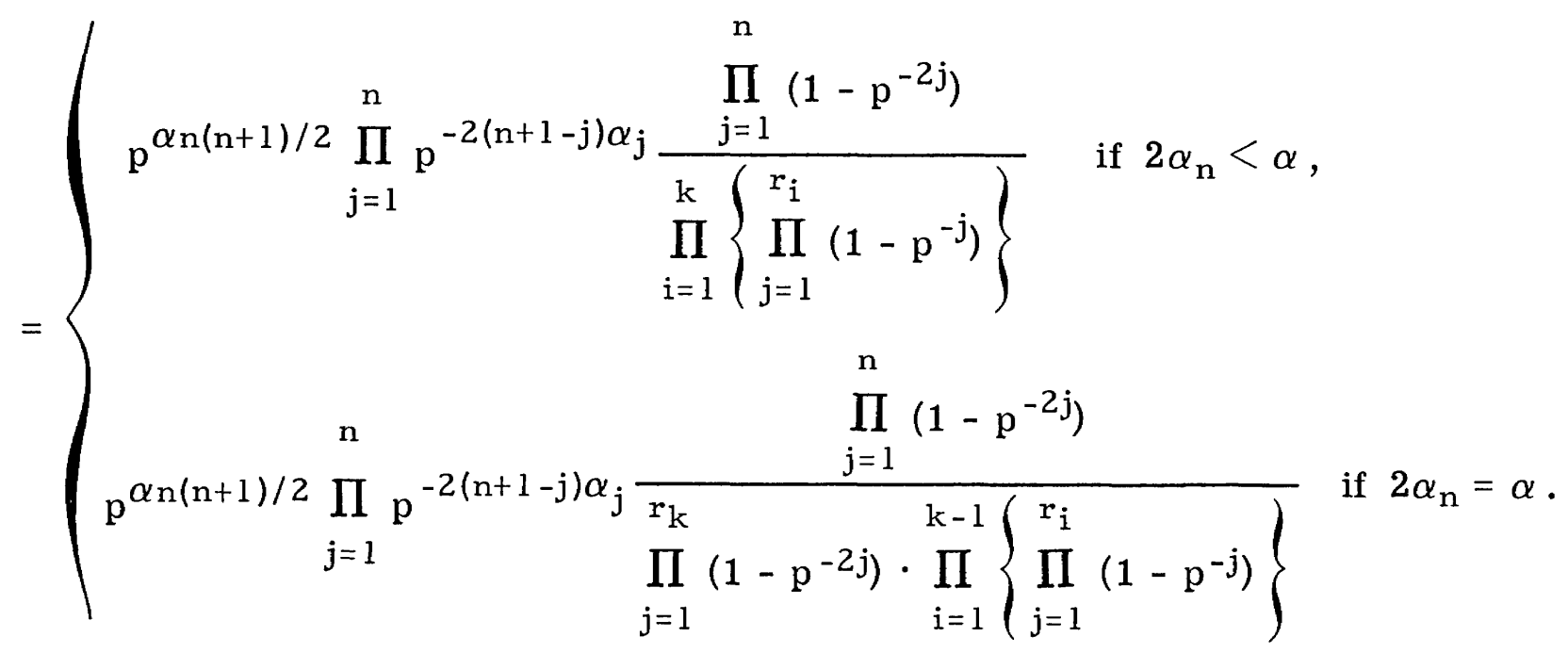

Since $\left[\mathscr{M}_{\mathrm{n}}: \mathrm{K}_{\mathrm{n}}\right]=\mathrm{A}_{2 \mathrm{n}}\left(\mathrm{p}^{\alpha_{1}}, \mathrm{p}^{\alpha_{2}}, \cdots, \mathrm{p}^{\alpha_{2 n}}\right)$ and

$$
\mathrm{h}_{\mathrm{n}}\left(\mathrm{p}^{\alpha}\right)=\sum \mathrm{A}_{2 \mathrm{n}}\left(\mathrm{p}^{\alpha}{ }_{1}, \mathrm{p}^{\alpha_{2}}, \cdots, \mathrm{p}^{\left.\alpha_{2 \mathrm{n}}\right)},\right.
$$

the summation being over all 2 -tuples $\left(\alpha_{1}, \alpha_{2}, \cdots, \alpha_{2 n}\right)$ of nonnegative integers satisfying (5), we can calculate $h_{n}(m)$ in a finite number of steps.

\section{REFERENCES}

1. N. J. Fine and I. Niven, The probability that a determinant be congruent to a $(\bmod m)$. Bull. Amer. Math. Soc. 50 (1944), 89-93.

2. C. C. MacDuffee, The theory of matrices. Chelsea Publ. Co., New York, 1946.

3. M. Newman and J. R. Smart, Symplectic modulary groups. Acta Arith. 9 (1964), 83-89.

4. C. L. Siegel, Symplectic geometry. Amer. J. Math. 65 (1943), 1-86.

5. E. Spence, m-symplectic matrices. Trans. Amer. Math. Soc. (to appear). 